\title{
Ageing of Pipes and Sustainability of Water Supply
}

\author{
A. H. R. Ratnasooriya and N. T. S. Wijesekara
}

\begin{abstract}
With ageing, the sustainability of the level of service of water supply in a pipe network may be adversely affected due to the reduction of flow rates caused by corrosion or scale deposition in pipes. In this study, attention is focussed on the effect of scaling on frictional losses in pipes and increased roughness values for pipes, based on experimental investigations, are presented. The influence of scaling on the performance of a small pipe network is analysed and relevant design issues are discussed.
\end{abstract}

Keywords: Ageing, Pipe Flow, Scale Deposition, Friction Loss

\section{Introduction}

The ability to predict the hydraulic performance of a water supply pipe network plays an important role in sustaining the level of supply during its working life. The effective roughness on which the friction factor is based and the nominal diameter of pipes are two essential parameters in determining the flow rates in pipe networks, the values of which are usually known for commercially used new pipes. However, with ageing, corrosion and scaling in pipes may cause an increase in effective roughness and a decrease in diameter, leading to a reduction of carrying capacity and the inability to sustain the level of supply. In this study, attention is focused on the effect of scale deposition on frictional losses in commercially used PVC pipes.

\section{Frictional Losses in Pipes}

The complex nature of turbulent flow of water in pipes has made the theoretical developments related to the flow resistance dependant on experimentally derived information. Among the industrial pipe friction formulae, the DarcyWeisbach equation is perhaps more rationally based than the other empirical formulations. In the Darcy-Weisbach equation, the head Inss due to friction hf is expressed as,

$$
h_{f}=4 f \frac{L}{D} \frac{v^{2}}{2 g}
$$

$$
\text { where } \quad \begin{aligned}
\mathrm{f} & =\text { Darcy friction factor } \\
\mathrm{L} & =\text { pipe length } \\
\mathrm{D} & =\text { pipe diameter } \\
\mathrm{V} & =\text { pipe flow velocity } \\
\mathrm{g} & =\text { acceleration due to gravity }
\end{aligned}
$$

The transitional turbulent nature of the pipe flow usually encountered in practice makes the Darcy friction factor dependent on the roughness of the pipe material and the Reynolds Number of flow. The Darcy friction factor can be determined by the Colebrook-White equation,

$\frac{1}{\sqrt{f}}=-4 \log _{10}\left[\frac{1}{3.71}\left(\frac{k}{D}\right)+\frac{1.26}{\operatorname{Re} \sqrt{f}}\right] \ldots \ldots$

where $k=$ effective roughness of pipe (mm)

$\operatorname{Re}=$ Reynolds Number and

$\operatorname{Re}=\frac{v D}{v}$

where $=$ coefficient of kinematic viscosity

In rough turbulent flow at higher values of Reynolds Number, the equation (2) approaches,

$\frac{1}{\sqrt{f}}=-4 \log _{10}\left(\frac{k}{D}\right)+2.28$

indicating the dependence of the Darcy friction factor only on the roughness of the pipe.

A. H. R. Ratnasooriya, B.Sc.Eng.(Hons) (Moratuwa) M.Phil (Moratuwa), Senior Lecturer, Department of Civil Enginteering, University of Moratuwa, Sri Lanka.

Eng. (Prof.) N. T. S. Wijesekara, C. Eng., FIE(Sri I.anka), B.Sc.Eng.Hons. (Sri Lanka), PG.Dip (Moratuwa), M.Eng. (Tokyo), D.Eng. (Tokyo), MICE(UK), Professor, Department of Civil Engineering, University of Moratuwa, Sri Lanka. 


\section{Effect of Ageing}

The effect of ageing on frictional losses in pipes has been studied by several investigators. Early studies reported in Russell [7], studies by Freeman [3] reported in Moody [5] and Davis \& Sorenson [1] are quoted in Echavez [2] who recently conducted studies on the effect of corrosion on frictional losses in pipes.

A linear increase of effective roughness of a pipe with time leading to the expression,

$k=k_{0}+\alpha t$

where $k=$ effective roughness after time $t$

$k_{0}=$ effective roughness for new pipe material

$\alpha=$ growth rate

is presented in Rouse [6]-based on the work of Colebrook-White and in Idelchick [4].

The value of $\alpha$ primarily depends on the quality of water and, although typical ranges are reported in literature, accurate values need to be obtained by testing of aged pipes.

Echavez [2] conducted a detailed study to investigate the hydraulic behaviour of Galvanized Iron (GI) and Copper pipes up to 50 $\mathrm{mm}$ in diameter that have been used for periods up to 50 years and found that in GI pipes, the increase in effective roughness with age followed a parabolic law instead of the linear variation reported in literature. The study also revealed that, in GI pipes, the Darcy friction factor increased 2.86 times on average due to corrosion over a period of 50 years and, in Copper pipes, no appreciable changes of Darcy friction factor occurred over a period of 30 years.

\section{Scaling in Pipes}

PVC pipes, used in a water supply pipe network in the Puttalam area over a period of time were tested in this study. Water quality tests [8] revealed the presence of $\mathrm{Ca}++$ and scaling was found in many pipes, as shown in Figure 1. Scale deposits were nearly uniform in thickness so that approximately circular cross sections of flow had been maintained and, except in a few pipes, were continuous throughout the test length. Local narrowing of pipes due to heavy scaling, as shown in Figure 2, was observed at points where imperfections of inner pipe wall were found.

The degree of roughness of scale deposits varied from pipe to pipe and, for comparative purposes, was categorised qualitatively as $\operatorname{High}(\mathrm{H}), \operatorname{Medium}(\mathrm{M}), \operatorname{Low}(\mathrm{L})$ or Very Low(VL) based on a visually observed scale, as indicated in Table 1.

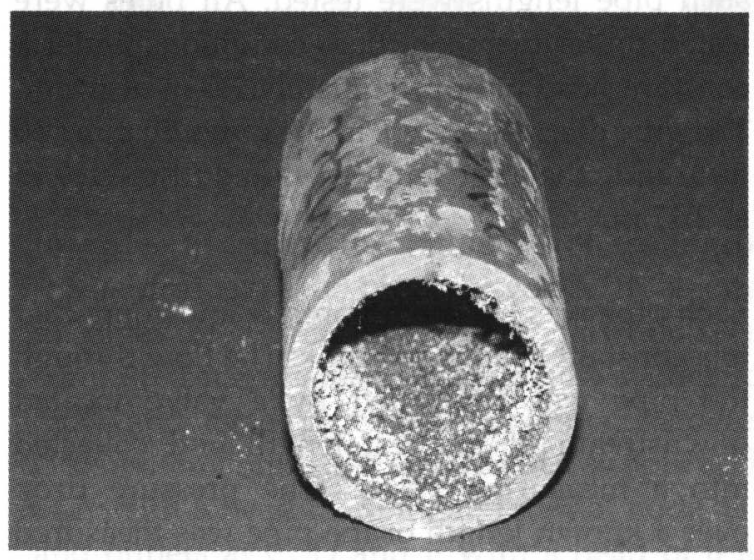

Figure 1 - Scale Deposit in a Pipe

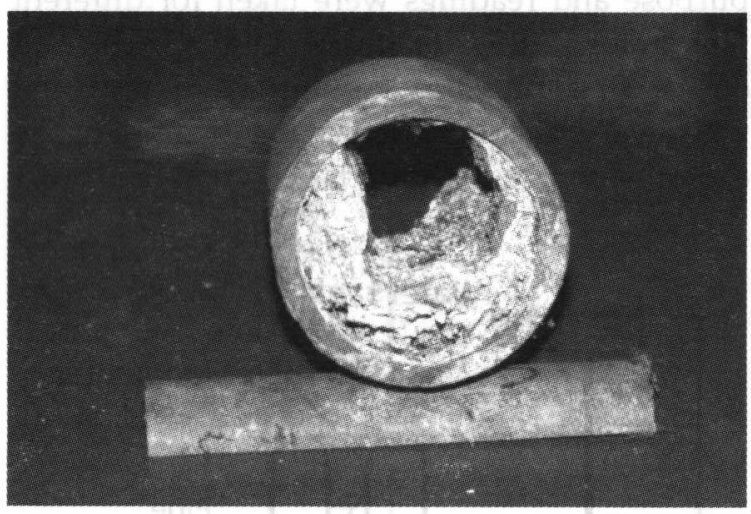

Figure 2-Local Narrowing due to Heavy Scaling

Table 1 - Scale Deposit Characteristics

\begin{tabular}{|c|c|}
\hline Category & $\begin{array}{c}\text { Description } \\
\text { (Visually observed) }\end{array}$ \\
\hline $\mathrm{H}$ & $\begin{array}{c}\text { Rough surface texture. } \\
\text { Individual surface } \\
\text { irregularities clearly visible. }\end{array}$ \\
\hline $\mathrm{M}$ & Rough surface texture \\
\hline $\mathrm{L}$ & Smooth surface texture \\
\hline $\mathrm{VL}$ & $\begin{array}{c}\text { Smooth surface texture, } \\
\text { Deposit not continuous }\end{array}$ \\
\hline
\end{tabular}




\section{Experimental Study}

Tests were carried out to determine the frictional head losses in pipes used in the water supply pipe network. As the head loss at a local narrowing due to heavy scaling is more representative of a local head loss, in order to investigate the effect of the increased roughness due to scaling on frictional losses, pipe lengths with no local narrowing were considered for testing and ten such pipe lengths were tested. All pipes were tested under turbulent flow conditions under a constant head of approximately $7.5 \mathrm{~m}$ of water. The pipe diameters were in the range $20 \mathrm{~mm}-50$ $\mathrm{mm}$ and the test lengths varied from $1.17 \mathrm{~m}$ to $2.42 \mathrm{~m}$.

Each pipe was fixed horizontally and connected to a constant head water tank. The flow through the pipe was controlled by a valve located downstream of the test length and collected into a measuring vessel. The pressure drop over a known length of the pipe was measured under steady flow conditions. A vertical U tube mercury manometer was used for this purpose and readings were taken for different flow rates. Sufficient entry lengths upstream of the first pressure tapping were provided whenever possible. A schematic diagram of the experimental test set up is shown in Figure 3.

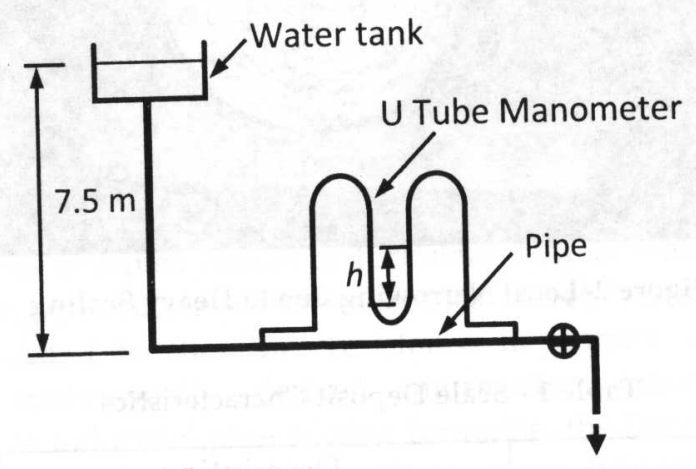

Figure 3 - Experimental Test Set Up

The reduction in diameter due to scaling was taken into account by the concept of 'effective diameter'. It was determined by measuring the volume of water required to fill the test length and calculating the diameter by assuming a uniform circular cross section along the test length.

\section{Analysis of Results}

The Darcy friction factor for different values of Reynolds Number was determined for each pipe by the equation (1). The results revealed that the range of flow in the tests included both transitional and rough turbulent regimes, depending on the relative roughness $(k / D)$ of pipes and the Reynolds Number which varied in the range 6,500-400,000.

In view of the dependence of the Darcy friction factor on the relative roughness of pipes, as indicated in equation (2), expressions based on the least square regression technique were developed to estimate its value for each pipe. The derivation of these expressions is given in the Appendix 1. The surface roughness of aged pipes, as expressed by the corresponding effective roughness values were based on the effective diameter, taking into account the thickness of scale deposits. The values of effective roughness of aged pipes obtained are shown in Table 2.

Table 2 - Effective Roughness of Aged Pipes

\begin{tabular}{|c|c|c|c|c|}
\hline Pipe & $\begin{array}{c}\text { Roughness } \\
\text { Category }\end{array}$ & $\begin{array}{c}\text { Effective } \\
\text { Diameter } \\
\boldsymbol{D}(\mathbf{m m})\end{array}$ & $(\boldsymbol{k} / \mathrm{D})$ & $\begin{array}{c}\boldsymbol{k} \\
(\mathbf{m m})\end{array}$ \\
\hline 1 & VL & 24.61 & 0.0004 & 0.009 \\
\hline 2 & $\mathrm{M}$ & 28.94 & 0.00323 & 0.093 \\
\hline 3 & $\mathrm{M}$ & 18.14 & 0.0057 & 0.103 \\
\hline 4 & $\mathrm{VL}$ & 50.34 & 0.0025 & 0.126 \\
\hline 5 & $\mathrm{~L}$ & 27.89 & 0.0056 & 0.156 \\
\hline 6 & $\mathrm{~L}$ & 24.62 & 0.0102 & 0.251 \\
\hline 7 & $\mathrm{~L}$ & 23.19 & 0.0155 & 0.359 \\
\hline 8 & $\mathrm{~L}$ & 48.65 & 0.01225 & 0.596 \\
\hline 9 & $\mathrm{H}$ & 27.98 & 0.0360 & 1.007 \\
\hline 10 & $\mathrm{H}$ & 37.64 & 0.124 & 4.667 \\
\hline
\end{tabular}

The results indicate a wide range of effective roughness values ranging from $0.009 \mathrm{~mm}$ to $4.667 \mathrm{~mm}$ representing the varied degree of roughness observed in the pipes. Nearly all the values are significantly higher than the effective roughness value of $0.03 \mathrm{~mm}$ recommended for new PVC pipes indicating the impact of scaling on the range of pipes tested leading to the reduction in carrying capacity in aged pipes. Although not fully consistent with the roughness values determined by the analysis, the visually based categorisation of the degree of roughness, shown in Table 1, serves an approximate guide in identifying the level of change in roughness due to scale deposition. 
The Darcy friction factor based on the regression analysis is shown in the form of the 'Moody Diagram' for the four categories of roughness VL (Pipe 4), L (Pipe 5), M (Pipe 3) and H (Pipe 9) in Figures 4, 5, 6 and 7 respectively.

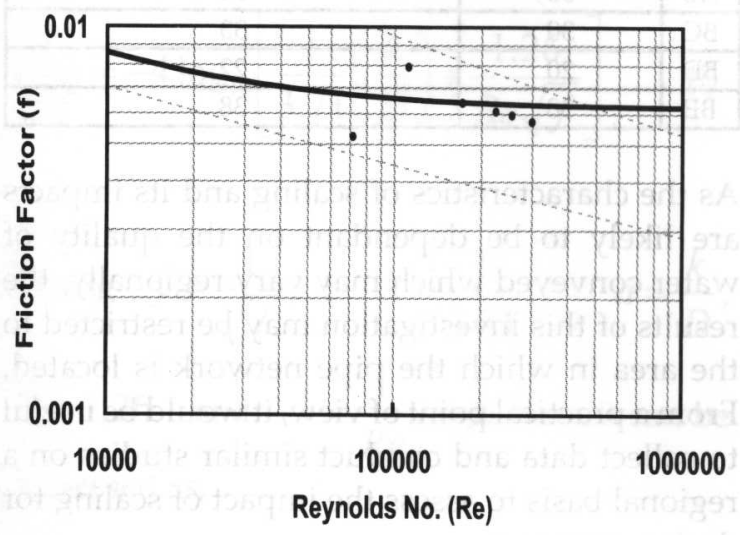

Figure 4 - Variation of Friction Factor (Pipe 4)

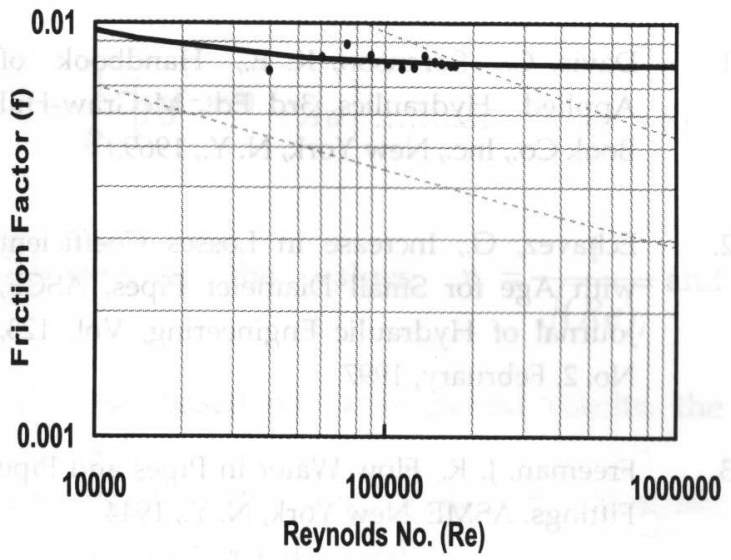

Figure 5 - Variation of Friction Factor (Pipe 5)

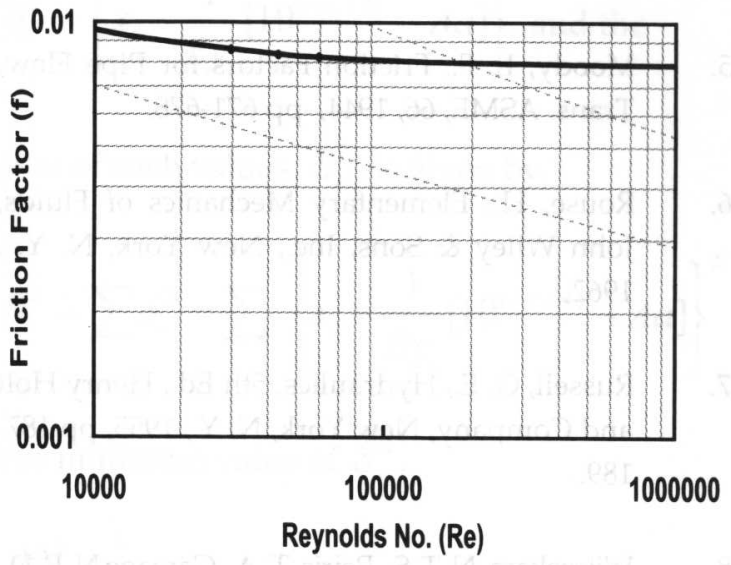

Figure 6 - Variation of Friction Factor (Pipe 3)

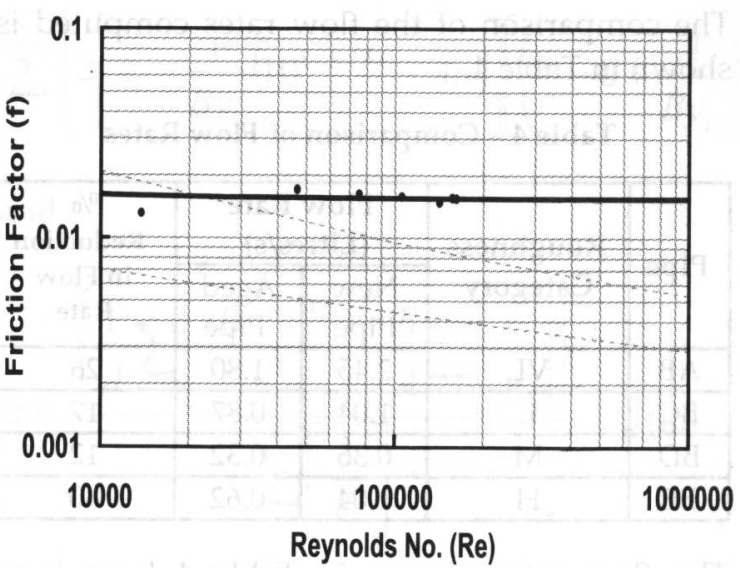

Figure 7 - Variation of Friction Factor (Pipe 9)

In order to assess the influence of scaling on the performance of pipe networks, flow rates in pipes of a small part of a network were computed using effective roughness values for 'new' and 'aged' pipes. The network considered is shown in Figure 8. It consists of a supply node at $A$ with a head of $10 \mathrm{~m}$, an internal node at $B$ and outlets at C, D and E with a head of $0 \mathrm{~m}$. The length, diameter and effective roughness values of pipes considered are given in Table 3 in which the effective roughness values for 'aged pipes' were selected from Table 2 to represent the visually observed roughness categories VL, $\mathrm{L}, \mathrm{M}$ and $\mathrm{H}$.

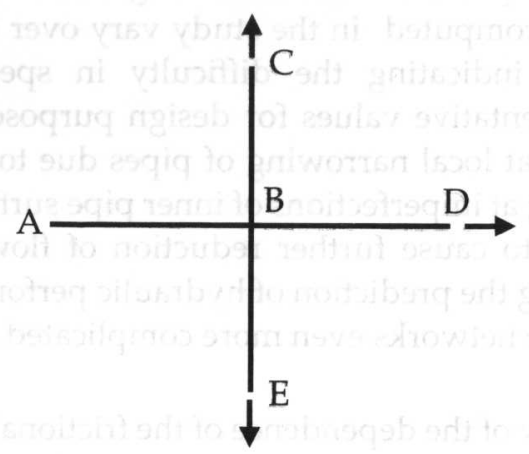

Figure 8 - Pipe Network

Table 3 - Pipe Network Characteristics

\begin{tabular}{|c|c|c|c|c|}
\hline & \multirow{2}{*}{ Pipe } & $\begin{array}{c}\text { Length } \\
\text { (m) }\end{array}$ & $\begin{array}{c}\text { Diameter } \\
\text { (mm) }\end{array}$ & \multicolumn{2}{|c|}{$\begin{array}{c}\text { Effective } \\
\text { Roughness } \\
\text { (mm) }\end{array}$} \\
\cline { 4 - 5 } & & & $\begin{array}{c}\text { New } \\
\text { Pipe }\end{array}$ & $\begin{array}{c}\text { Aged } \\
\text { Pipe }\end{array}$ \\
\hline AB & 100 & 50 & 0.03 & 0.126 \\
\hline BC & 100 & 30 & 0.03 & 0.156 \\
\hline BD & 100 & 20 & 0.03 & 0.103 \\
\hline BE & 100 & 30 & 0.03 & 1.007 \\
\hline
\end{tabular}


The comparison of the flow rates computed is shown in Table 4.

Table 4 - Comparison of Flow Rates

\begin{tabular}{|c|c|c|c|c|}
\hline \multirow{2}{*}{ Pipe } & \multirow{2}{*}{$\begin{array}{c}\text { Roughness } \\
\text { Category }\end{array}$} & \multicolumn{2}{|c|}{$\begin{array}{l}\text { Flow Rate } \\
\text { (Litres/s) }\end{array}$} & \multirow{2}{*}{$\begin{array}{c}\% \\
\text { Reduction } \\
\text { in Flow } \\
\text { Rate }\end{array}$} \\
\hline & & $\begin{array}{l}\text { New } \\
\text { Pipe }\end{array}$ & $\begin{array}{l}\text { Aged } \\
\text { Pipe }\end{array}$ & \\
\hline $\mathrm{AB}$ & $\mathrm{VL}$ & 2.45 & 1.80 & 26 \\
\hline $\mathrm{BC}$ & $\mathrm{L}$ & 1.04 & 0.87 & 17 \\
\hline $\mathrm{BD}$ & $M$ & 0.36 & 0.32 & 12 \\
\hline $\mathrm{BE}$ & $\mathrm{H}$ & 1.04 & 0.62 & 40 \\
\hline
\end{tabular}

The flow rates shown in Table 4 have been computed by considering only the frictional head losses. In spite of neglecting the additional losses at local narrowings due to heavy scaling, the values shown clearly indicate the adverse impact of scaling on the hydraulic performance of the pipe network.

\section{Concluding Remarks}

The results of an investigation carried out to study the effect of scaling on the performance of pipe networks have been presented. The investigation reveals that substantial reduction in flow rates could be caused by the increased frictional resistance due to scale deposition in pipes. Depending on the characteristics of the scale deposit, the increased roughness values of pipes computed in the study vary over a wide range indicating the difficulty in specifying representative values for design purposes. The losses at local narrowing of pipes due to heavy scaling at imperfections of inner pipe surface are likely to cause further reduction of flow rates making the prediction of hydraulic performance of pipe networks even more complicated.

In view of the dependence of the frictional losses on pipe diameter, in addition to the relative roughness, as indicated in equation (1), the adverse impact of scaling may be compensated by providing larger sizes for the pipes in the network. The increased diameters required for the pipes in the network shown in Figure 8, in order to maintain the same hydraulic performance in spite of scale deposition, are given in Table 5. These values are based on frictional resistance under rough turbulent flow conditions. In addition, reducing the locations of imperfections of inner pipe surface and locating pipes in an easily replaceable manner whenever possible are among the practices that can be adopted to reduce the adverse impacts of scaling in pipes.
Table 5 - Pipe Diameters Required to Maintain the Same Hydraulic Performance

\begin{tabular}{|c|c|c|}
\hline Pipe & $\begin{array}{c}\text { Initial } \\
\text { Diameter } \\
(\mathbf{m m})\end{array}$ & $\begin{array}{c}\text { Diameter Required to Maintain } \\
\text { Same Hydraulic Performance } \\
\text { (mm) }\end{array}$ \\
\hline $\mathrm{AB}$ & 50 & 54 \\
\hline $\mathrm{BC}$ & 30 & 33 \\
\hline $\mathrm{BD}$ & 20 & 22 \\
\hline $\mathrm{BE}$ & 30 & 38 \\
\hline
\end{tabular}

As the characteristics of scaling and its impacts are likely to be dependant on the quality of water conveyed which may vary regionally, the results of this investigation may be restricted to the area in which the pipe network is located. From a practical point of view, it would be useful to collect data and conduct similar studies on a regional basis to assess the impact of scaling for design purposes.

\section{References}

1. Davis, C., Sorenson, K. E., Handbook of Applied Hydraulics, 3rd Ed., McGraw-Hill Book Co., Inc., New York, N. Y., 1969.

2. Echavez, G., Increase in Losses Coefficient with Age for Small Diameter Pipes, ASCE, Journal of Hydraulic Engineering, Vol. 123, No. 2, February, 1997.

3. Freeman, J. R., Flow Water in Pipes and Pipe Fittings, ASME, New York, N. Y., 1944.

4. Idelchik, I. E., Handbook of Hydraulic Resistance, 3rd Ed., CRC press, Inc., Boca Raton, Fla., 1994.

5. Moody, L. F., Friction Factors for Pipe Flow, Trans. ASME, 66, 1944, pp 671-678.

6. Rouse, H., Elementary Mechanics of Fluids, John Wiley \& Sons, Inc., New York, N. Y. , 1962.

7. Russell, G. E., Hydraulics, 5th Ed., Henry Holt and Company, New York, N. Y., 1955, pp 187189.

8. Wijesekara, N. T.S., Peiris, T. A., Gamage N.P. D., Koddipili, A. A., Gnanapala, P. P., Amarasinghe, C. B., Ginige, G. K. de S., Study on Water Supply System of the Puttalam Cement Company Ltd, Project Report, Department of Civil Engineering, University of Moratuwa, 2000. 


\section{Appendix I}

For transitional turbulent flow, the ColebrookWhite equation is expressed as,

$\frac{1}{\sqrt{f}}=-4 \log _{10}\left[\frac{1}{3.71}\left(\frac{k}{D}\right)+\frac{1.26}{\operatorname{Re} \sqrt{f}}\right]$

Taking $\quad y=\frac{1}{\sqrt{f}}, \quad A=\frac{1}{3.71}, \quad a=\frac{k}{D}$, $B=1.26$ and $x=\frac{1}{R e}$, equation (i) can be expressed as,

$y=-4 \log _{10}[A a+B x y]$ yielding

$x=\frac{1}{B y}\left[10^{(-y / 4)}-A a\right]$

Considering the values $x_{i}=\frac{1}{\sqrt{(\operatorname{Re})_{i}}}$ and $y_{i}=\frac{1}{\sqrt{f_{i}}}$ based on experimental results, the square of the error due scatter of experimental data, $\delta_{i}^{2}$, can be expressed as,

$$
\delta_{i}^{2}=\left\{x_{i}-\frac{1}{B y_{i}}\left[10^{\left(-y_{i} / 4\right)}-A a\right]\right\}^{2} \text { and the }
$$

sum of such values, $S_{r}^{2}$, is given by,

$$
S_{r}^{2}=\sum \delta_{i}^{2}=\sum\left\{x_{i}-\frac{1}{B y_{i}}\left[10^{\left(-y_{i} / 4\right)}-A a\right]\right\}^{2}
$$

For minimum value of $S_{r}^{2}$,

$\frac{d S_{r}^{2}}{d a}=0$ yielding,

$$
\sum\left\{2\left[x_{i}-\frac{1}{B y_{i}}\left(10^{\left(-y_{i} / 4\right)}-A a\right)\right]\left[\left(0-0+\frac{A}{B y_{i}}\right)\right]\right\}
$$

and

$$
a=\frac{\left\{\frac{1}{A} \sum\left[\frac{10^{\left(-y_{i} / 4\right)}}{y_{i}^{2}}\right]-\frac{B}{A} \sum\left[\frac{x_{i}}{y_{i}}\right]\right\}}{\sum\left[\frac{1}{y_{i}^{2}}\right]} \ldots
$$

For fully turbulent flow, $B=0$ and from equation (iii),

$$
a=\frac{\left\{\frac{1}{A} \sum\left[\frac{10^{\left(-y_{i} / 4\right)}}{y_{i}^{2}}\right]\right\}}{\sum\left[\frac{1}{y_{i}^{2}}\right]}
$$

